\title{
Vol. 70, No. 37
}

In the report "Post-Acute Sequelae of SARS-CoV-2 Infection Among Adults Aged $\geq 18$ Years — Long Beach, California, April 1-December 10, 2020," on page 1276, in the first full paragraph the first sentence should have read, "In the multivariable regression model, the odds of experiencing symptoms 2 months after a positive SARS-CoV-2 test result were significantly higher among females $(\mathrm{aOR}=2.83)$, persons with at least one preexisting condition $(\mathrm{aOR}=2.17)$, and those aged 40-54 years (versus 25-39 years) $(\mathrm{aOR}=1.86)$ (Table 3$). "$ 